Dhaka Univ. J. Biol. Sci. 26(1): 77-82, 2017 (January)

\title{
EFFECT OF REARING DENSITY ON REPRODUCTION AND EMBRYOGENESIS OF ZEBRAFISH DANIO RERIO (HAMILTON, 1822)
}

\author{
Md Golam Rabbane*, Md. Mizanur Rahman, \\ Md. Alamgir Kabir and Md. Hasan Faruque \\ Department of Fisheries, Faculty of Biological Sciences, University of Dhaka, \\ Dhaka-1000, Bangladesh
}

Key words: Rearing density, Reproduction, Embryogenesis, Zebrafish

\begin{abstract}
Effect of rearing density $\left(5,15,25,35\right.$ and 45 fish $\left.\lambda^{2}\right)$ on reproductive performances such as spawning success, fertilization rate, hatching rate and embryogenesis in terms of per cent survival rate of embryos at cleavage, gastrula, segmentation, pharyngula and hatching were evaluated. Survival, hatching, fertilization rate and per cent survivability of embryos did not differ significantly between the treatments 1,2 and 3 , but showed significant difference $(p<0.05)$ between 4 and 5 . Treatment three $\left(25\right.$ fish $\left.A^{2}\right)$ had five-folds higher number of successful progeny than treatment one. Results suggest that 25 fish $\wedge^{2}$ can be used as optimum rearing density.
\end{abstract}

\section{Introduction}

Zebrafish Danio rerio is an inhabitant of freshwater of tropical region. The fish is small shoaling cyprinid fish(1) widely distributed throughout south and south-east Asia, with maximum species diversity in north-eastern India, Myanmar and Bangladesh(2). Zebrafish is one of the most important aquarium fish and has been used as a model organism in different fields of biology including genetics, developmental biology, biomedicine, neurophysiology etc.(3-5) because of its unique features such as, optical clarity of the embryo, amenability to genetic manipulation, and tolerance of a wide range of environmental conditions(5). Several transgenic strains have been produced by modified zebrafish(6). However, the husbandry conditions of this fish have not been yet optimized. Therefore, husbandry questions remain unsolved, including how rearing density affects the reproduction and embryogenesis of zebrafish(5).

Stocking density is one of the key factors that influence the perceived level of stress in fish $^{(7)}$. Inappropriate rearing densities may impair the growth and reduce immune competence due to factors such as social interaction and the deterioration of water quality, which can affect the reproduction, survivability, the performance of embryogenesis and feed conversion efficiency of the fish ${ }^{(8-10)}$. Moreover, rearing density

*Author for correspondence: <rabbane@du.ac.bd>. 
of larvae significantly influences the growth rates and final larval survival(11). The objective of this study was to identify the effects of rearing density on reproduction and embryogenesis of zebrafish.

\section{Methods and Materials}

Zebrafish, Glotype (red) was used in this study. One month old fish were purchased from Kataban aquarium fish market, Dhaka, Bangladesh. Glass made 15 tanks of $16 \mathrm{~cm}^{3}$ each were set up in a laboratory at the Department of Fisheries, University of Dhaka, Bangladesh. The tanks were washed properly with detergent before stocking the fish. Then the tanks were filled with clean tap water.

The experiment was designed with 5 treatments in triplicates. Zebrafish were randomly stocked in 15 tanks at five treatments of stocking densities as T1, T2, T3, T4 and $\mathrm{T} 5$ corresponding to $5,15,25,35,45$ fish.litre $^{-2}$ of water. Fish were fed to satiation level twice a day at 7 a.m. and 6 p.m. with commercial pellet (TetraBits ${ }^{\circledR}$ Complete, Tetra $\mathrm{GmbH}, \mathrm{Germany)}$. The ingredients of diet were as protein $47.5 \%$, oil $6.5 \%$, ash $10.5 \%$, moisture 6\%; additives: vitamin A $29770 \mathrm{IU} / \mathrm{kg}$, vitamin D31860 IU $/ \mathrm{kg}$, vitamin E 200 $\mathrm{mg} / \mathrm{kg}$, L-ascorbyl-2-polyphosphate $137 \mathrm{mg} / \mathrm{kg}$. Aeration was given to each tank by using air pump. Water was siphoned manually in every two days.

After 2-months rearing, 5 pairs of matured male and female were collected from each treatment to observe their reproductive performance. Each pair with one male and one female was hold in $1 \mathrm{~L}$ capacity breeding tank as Beta tank for mating. These breeding tanks were specially made and composed of one transparent separation sheet, one perforated bottom plate and a plastic box. These tanks were purchased from local market. Thus, total 25 pairs of male and female fish were hold separately in 25 breeding tanks for mating. During breeding period the temperature and photoperiod of $14 \mathrm{hrs}$ of light and $10 \mathrm{hrs}$ dark period were strictly maintained. After spawning, the eggs were collected into Petri dishes and incubated at $28.5^{\circ} \mathrm{C}$. Percent spawning success, fertilization rate and hatching rate were measured using the following formulas ${ }^{(5)}$. Survival rate was also counted during different stages of embryogenesis. The following stages were observed under microscope: zygote period $(0-3 / 4 \mathrm{~h})$, cleavage period $(3 / 4-2$ $1 / 4 \mathrm{hrs})$, blastula period $\left(2^{1 / 4}-5^{1 / 4} \mathrm{hrs}\right)$, gastrula period ( $\left.5 \frac{1 / 4}{4} 10 \mathrm{hrs}\right)$, segmentation period (10 - $24 \mathrm{hrs}$ ), pharyngula period ( $24-48 \mathrm{hrs})$, hatching period ( $48-72 \mathrm{hrs})$.

Percent spawning success $=\frac{\text { Total number of successful spawns at a given density }}{\text { Total number of crosses }} \times 100$

Fertilization rate $(\%)=\frac{\text { Number of fertilized embryos }}{\text { Total number of embryos produced during a spawning event }} \times 100$ 
Hatching rate $(\%)=\frac{\text { Number of hatched embryos }}{\text { Total number of embryos produced during a spawning event }} \times 100$

The water temperature $\left({ }^{\circ} \mathrm{C}\right), \mathrm{pH}$, dissolved oxygen $(\mathrm{mg} \Lambda)$ and conductivity $(\mathrm{ms} / \mathrm{cm})$, were measured using bench photometer (Model HI 9828, HANNA Instruments, Woonsocket RI-USA).

Data were analyzed statistically by one-way ANOVA and Tukey test ${ }^{(12)}$ using SPSS software (version 16.0, SPSS Inc., Chicago, USA) with the level of significance at $p<0.05$.

\section{Results and Discussion}

Significantly higher spawning successes were found in T1 $(86.66 \pm 6.66 \%)$ when compared with T4 $(45.83 \pm 4.16 \%)$ and T5 $(50 \pm 0 \%)$ treatments (Fig. 1). However there is no significant difference between T2 $(72.21 \pm 5.55 \%)$ and T3 $(72.21 \pm 5.55 \%)$ whereas T2 had significantly higher spawning success than $\mathrm{T} 4$.

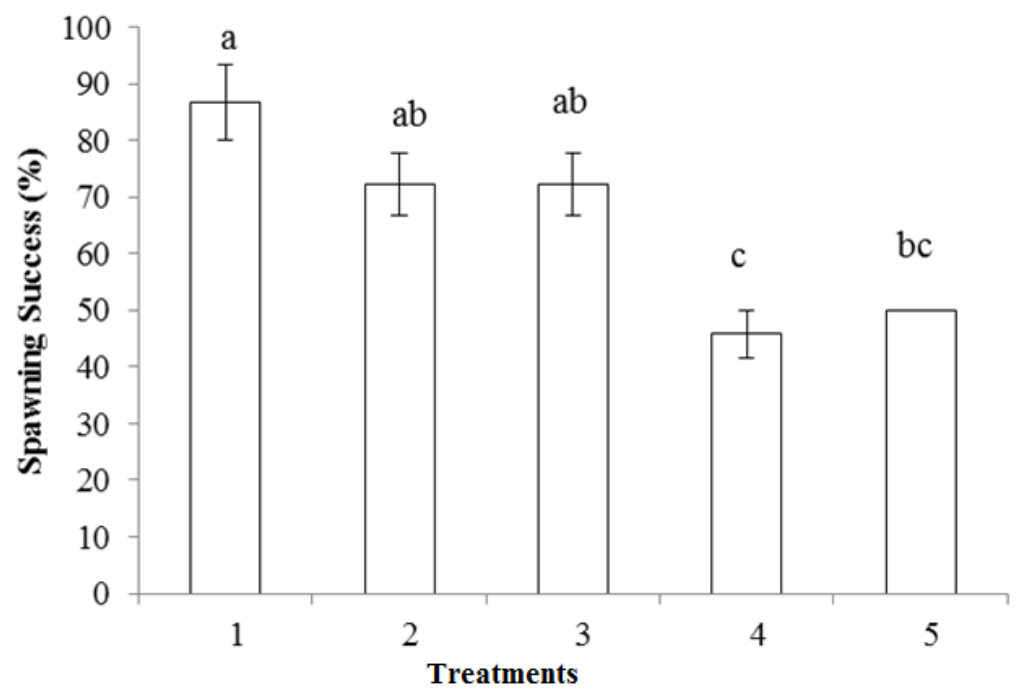

Fig. 1. Spawning success of zebrafish Danio rerio in five treatments. Bars (mean $\pm \mathrm{SEM}$ ) with different letters denote significant differences ( $\mathrm{p}<0.05)$.

The observed results of stocking density on spawning success showed that the rate of spawning success is inversely proportional to rearing density. Rearing density is an important factor affecting growth of wild and laboratory fish ${ }^{(13-15)}$. High density of fish might have produced a stressful situation and toxic substances which could be the probable cause for lower per cent of spawning success in $\mathrm{T} 4$ and $\mathrm{T} 5^{(16)}$.

No significant differences were detected in hatching rate and fertilization rate in T1, T2 and T3 treatments (Figs 2 and 3). Similarly, there is no significant difference between 
T4 and T5. But the T1 $(56.41 \pm 2.86 \%)$, T2 $(56.03 \pm 3.67 \%)$ and T3 $(54.4 \pm 1.10 \%)$ had significantly higher hatch rate than T4 $(28.23 \pm 1.72 \%)$ and T5 $(28.23 \pm 1.38 \%)$. Fertilization rate of T1 $(88.72 \pm 5.16), \mathrm{T} 2(87.32 \pm 3.87)$ and $\mathrm{T} 3(84.36 \pm 1.04)$ was also significantly higher than T4 $(45.33 \pm 2.84)$ and $\mathrm{T} 5(47 \pm 2.08)$ treatments.

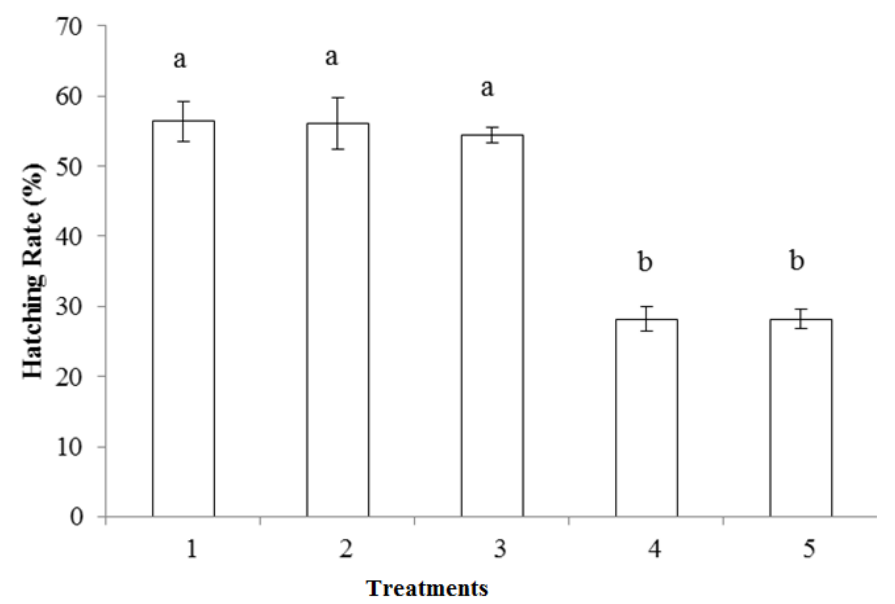

Fig. 2. Hatching rate of zebrafish Danio rerio in five treatments. Bars (mean $\pm \mathrm{SEM}$ ) with different letters indicate significant differences $(\mathrm{p}<0.05)$.

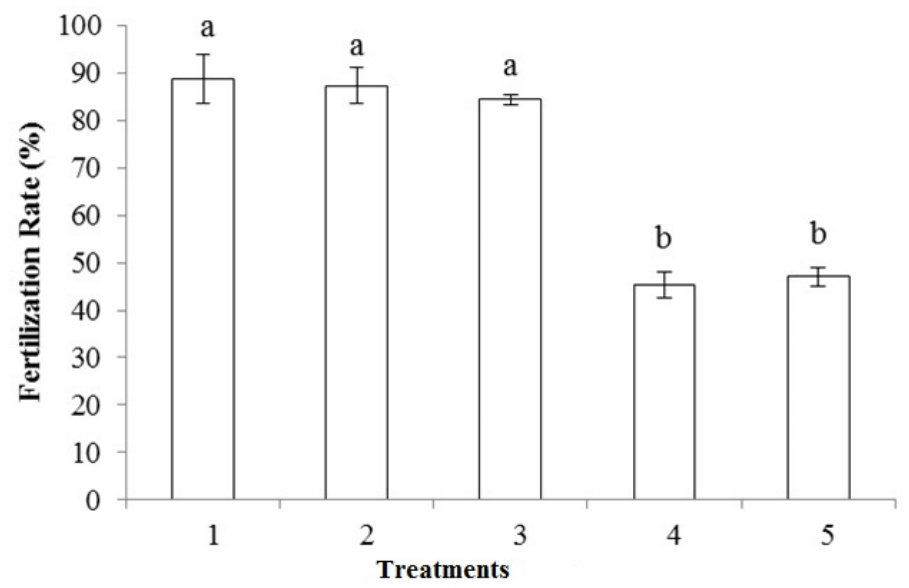

Fig. 3. Fertilization rate of zebrafish Danio rerio in five treatments. Bars (mean $\pm S E M$ ) with different letters are significantly different $(\mathrm{p}<0.05)$.

The observed result indicated that fertilization and hatching rate has decreased with the increase of stocking density. The lower hatching and fertilization rate could be the result of poor egg and sperm quality and insufficient nutrition due to higher stocking rate of fish ${ }^{(17-18)}$. Castronova et al.(5) found no negative impact on percent spawning success and fertilization rate of zebrafish stocked up to 12 fish $\mathrm{L}^{-2}$. They also observed 45 to $85 \%$ fertilization rate and 65 to $70 \%$ spawning rate. 
In this experiment, different developmental stages of embryogenesis were observed. Survival rates (\%) of embryos were calculated at different developmental stages (Table 1). In cleavage, pharyngula and hatching stages, $\mathrm{T} 1, \mathrm{~T} 2$ and $\mathrm{T} 3$ had greater survival rate than T4 and T5 stages. However there was no significant difference among T1, T2 and T3 treatments.

Table 1. Survival rate (\%) of embryos of zebrafish Danio rerio at different developmental stages. Mean $( \pm$ SEM) values with different superscript letters in each row indicate significant difference $(p<0.05)$.

\begin{tabular}{lccccc}
\hline \multirow{2}{*}{ Variables $(\%)$} & \multicolumn{5}{c}{ Treatments } \\
\cline { 2 - 6 } & 1 & 2 & 3 & 4 & 5 \\
\hline Cleavage & $88.72 \pm 5.16^{\mathrm{a}}$ & $87.32 \pm 3.87^{\mathrm{a}}$ & $84.36 \pm 1.04^{\mathrm{a}}$ & $45.33 \pm 2.84^{\mathrm{b}}$ & $47 \pm 2.08^{\mathrm{b}}$ \\
Gastrula & $70.90 \pm 0.40^{\mathrm{a}}$ & $67.36 \pm 1.14^{\mathrm{ab}}$ & $65.16 \pm 1.04^{\mathrm{b}}$ & $40.79 \pm 0.51^{\mathrm{c}}$ & $41.34 \pm 0.79^{\mathrm{c}}$ \\
Segmentation & $62.33 \pm 0.43^{\mathrm{a}}$ & $59.92 \pm 0.59^{\mathrm{ab}}$ & $57.27 \pm 1.05^{\mathrm{b}}$ & $35.43 \pm 1.12^{\mathrm{c}}$ & $36.22 \pm 1.01^{\mathrm{c}}$ \\
Pharyngula & $58.06 \pm 0.84^{\mathrm{a}}$ & $57.21 \pm 0.31^{\mathrm{a}}$ & $55.38 \pm 0.17^{\mathrm{a}}$ & $30.82 \pm 0.49^{\mathrm{b}}$ & $30.60 \pm 0.58^{\mathrm{b}}$ \\
Hatching & $56.41 \pm 2.86^{\mathrm{a}}$ & $56.03 \pm 3.67^{\mathrm{a}}$ & $54.4 \pm 1.10^{\mathrm{a}}$ & $28.23 \pm 1.72^{\mathrm{b}}$ & $28.23 \pm 1.38^{\mathrm{b}}$ \\
\hline
\end{tabular}

In gastrula and segmentation stages, $\mathrm{T} 1$ had significantly greater survival rate than T3, T4 and T5 treatments. However, there was no significant difference between T4 and T5. Embryogenesis is significantly influenced by the quality of egg and sperm and the quality of gamete is highly dependent on some external factors or broodstock management practices ${ }^{(19)}$. For this reasons, lower survival rate in T4 and T5 treatments could be the impact of higher stocking density. The water quality parameters were almost similar and in acceptable range in all treatments. Temperature, $\mathrm{pH}, \mathrm{DO}$ and conductivity were $27.13 \pm 0.31^{\circ} \mathrm{C}, 8.3 \pm 0.09,2.63 \pm 0.45 \mathrm{mgL}^{2}$ and $0.37 \pm 0.02 \mathrm{~ms} / \mathrm{cm}$, respectively.

Results suggests that stocking density of 25 fish $\Lambda^{2}$ can be used in studying the reproductive performance of zebrafish.

\section{Acknowledgements}

Authors are grateful to University Grants Commission of Bangladesh for their financial support to conduct this study.

\section{References}

1. Talwar PK and AG Jhingran 1991. Inland Fishes of India and Adjacent Countries. Oxford and I. B. H. Publishing, Calcutta.

2. Barman RP 1991. A Taxonomic Revision of the Indo-Burmese Species of Danio Hamilton Buchanan (Pisces, Cyprinidae) (Vol. 137). Zoological Survey of India.

3. Rubinstein AL 2003. Zebrafish: from disease modelling to drug discovery. Curr. Opin. Drug. Discov. Devel. 6: 218-223. 
4. Amsterdam A and N Hopkins 2006. Mutagenesis strategies in zebrafish for identifying genes involved in development and disease. Trends. Genet. 22: 473-478

5. Castranova D, A Lawton, C Lawrence, DP Baumann, J Best, J Coscolla, A Doherty, J Ramos, J Hakkesteeg, C Wang, C Wilson, J Malley and BM Weinstein 2011. The effect of stocking densities on reproductive performance in laboratory Zebrafish (Danio rerio). Zebrafish 8(3): 141-146.

6. White RM, A Sessa, C Burke, T Bowman, J LeBlanc, C Ceol and LI Zon 2008. Transparent adult Zebrafish as a tool for in vivo transplantation analysis. Cell Stem Cell 2(2): 183-189.

7. North BP, JF Turnbull, T Ellis, MJ Porter, H Migaud, J Bron and NR Bromage 2006. The impact of stocking density on the welfare of rainbow trout (Oncorhynchus mykiss). Aquaculture 255(1): 466-479.

8. Villagran ER 1993. Effects of stocking density, and supplemental feeding on production of red swamp crawfish in pools. Master's thesis. Louisiana State University, Baton Rouge, LA.

9. Ellis T, B North, AP Scott, NR Bromage, M Porter and D Gadd 2002.The relationships between stocking density and welfare in farmed rainbow trout. J. Fish Biol. 61(3): 493-531.

10. Rahman M, M Zaher, KM Azimuddin, S Yeasmine, M Khan and A Arshad 2013.Stocking density effects on growth and production of the threatened silurid catfish, Mystus cavasius (Hamilton) fingerlings in nursery ponds. Aquac. Res. 44(7): 1132-1139.

11. Mayden RL, KL Tang, KW Conway, J Freyhof, S Chamberlain, M Haskins and A Bufalino 2007. Phylogenetic relationships of Danio within the order Cypriniformes: A framework for comparative and evolutionary studies of a model species. J. Exp. Zool. Part B: Mole. Dev. Evol. 308(5): 642-654.

12. Steel RG and JH Torrie 1980. Analysis of Covariance. Principles and procedures of statistics: A Biometrical Approach, 401-437.

13. Smith RC and KS Baker 1978. Optical classification of natural waters. Limnol. Oceanogr. 23(2): 260-267.

14. Lutz CG and WR Wolters 1986. The effect of five stocking densities on growth and yield of red swamp crawfish Procambarus clarkii. J. World Aquacult. Soc. 17(1-4): 33-36.

15. Chakraborty BK, ZA Mirza, MI Miah, MAB Habib and Chakraborty A 2007. Reproductive cycle of the endangered sarpunti, Puntius sarana (Hamilton, 1822) in Bangladesh. Asian Fish. Sci. 20(1/2): 145-164.

16. Foss A, T Kristensen, Å Åtland, H Hustveit, H Hovland, AØfsti, and AK Imsland 2006. Effects of water reuse and stocking density on water quality, blood physiology and growth rate of juvenile cod (Gadus morhua). Aquaculture 256(1): 255-263.

17. Markovich ML, NV Rizzuto and PB Brown 2007. Diet affects spawning in zebrafish. Zebrafish 4: 69-74.

18. Kaushik S, L Georga and G Koumoundouros 2011. Growth and body composition of zebrafish (Danio rerio) larvae fed a compound feed from first feeding onward: toward implications on nutrient requirements. Zebrafish 8: 87-93.

19. Bobe J, C Labbe 2010. Egg and sperm quality in fish. General and Comparative Endocrinology 165: $535-548$. 